\title{
Theoretical Study on Steady Airflow through Multiple Upper Opennings inside a Rectangular Building in the Presence of Indirect Flow
}

\author{
A. L. Muhammad \\ Kano University of Science and \\ Technology, Wudil \\ Department of Mathematics
}

\author{
S. A. Ibrahim \\ School of General Studies \\ Kano State Polytechnic
}

\author{
D. A. Gano \\ Kano University of Science and \\ Technology, Wudil \\ Department of Mathematics
}

\author{
M. Z. Ringim \\ Kano University of Science and \\ Technology, Wudil \\ Department of Mathematics
}

\author{
A. B. Baffa \\ Bayero University, Kano
}

\begin{abstract}
The present paper is an extension of [2] work, in which, the study was concerned with an investigation of airflow through multiple upper vents in the presence of indirect flow, in which, the tendency of buoyancy force effect was strong due to the high temperature difference between interior and the ambient. A flow of this type represents a new class of boundary- layer flow problems in the building. Moreover, this is an exact solution of the complete Navier- Stokes Equations (including, buoyancy force term), which were then dimensionalised using some dimensionless parameters to reduce the Equations to ordinary differential Equations and then solved analytically by variation of parameter method and obtained the solutions, in which the behavior of parameters in the results were predicted the velocity, temperature profiles together with volumetric airflow and mass transfer. The results were then evaluated numerically for several sets of values of the parameters in order to ascertain the best for optimal ventilation. We performed comparison based on assume numerical values and parameter values of [2]. From the simulations in Figures 15-17, our Developed study is better and more efficient for ventilation. In conclusion, the main feature to be observed as the temperature changes increases the corresponding airflow is also increases this leads to the increase in velocity profiles. As the velocity of airflow increases the corresponding volumetric airflow is decreases, this leads to the increase in mass transfer in the building envelope. Therefore, the greater number of vertical vents in the building, and the greater temperature difference between the interior and exterior, the stronger is the effect of the buoyancy forces.
\end{abstract}

\section{General Terms}

Prandtl number, Grashof number, Discharge coefficient, Effective thermal coefficient.

\section{Keywords}

Velocity profiles, Temperature profiles, Volumetric airflow, Mass transfer.

\section{INTRODUCTION}

Natural ventilation of building provides improvement of internal comfort and air quality conditions leading to a significant reduction of cooling energy consumption. Design of natural ventilation systems for many types of building is based on buoyancy forces. However, external wind flow can have significant effects on buoyancy- driven natural ventilation. Of course natural ventilation is being pursued by humans, who are increasingly spending more time indoors, to extend the possibilities of living in uncongenial or squally conditions etc. The improvements of the quality of the interior space both in its attractiveness, spaciousness, luminosity, and more importantly its proper natural ventilation are major concerns for designers of modern structures. Considerable attention has been given to inter-zone heat transfer in passive solar and conventional buildings so that algorithm energy models were developed by [5]. Experimental and theoretical work has been carried out by various researchers to study natural convection via doorways in small- scale models and full- size rooms [6]. [10] studied a convective heat and mass transfer through large openings, which plays an important role in the thermal behavior in buildings. [1] airflow process in single-sided natural ventilation by using a computational fluid dynamics (CFD) method together with analytical and empirical models. [12] Considered building having two openings at different vertical level on opposite walls, the heights of the two openings are relatively small, and the areas of the top and bottom openings are $A_{t}$ and $A_{b}$ respectively. The study also considered an indoor source of heat $E$, and the wind force can assist or oppose the thermal buoyancy force, when the indoor temperature is uniform. [11] Presented an experimental and numerical analyses of heat transfer and air flow on an interactive building façade. [7] Investigated air flow rate across a vertical opening induced by a thermal source in a room, various parameters were used in designing natural ventilation. [9] Considered wind-driven cross ventilation in building with small openings. Airflow process across vertical vents induced by stack- driven effect with an opposing flow in one of the openings was presented by [2]. An investigation of stack- driven airflow through rectangular cross- ventilated building with two openings using analytic technique was also recently presented by [3]. [4] Presented a simple mathematical model of stack ventilation flows in multi-compartment buildings, with a view to providing an intuitive understanding of the physical processes governing the movement of air and heat through naturally ventilated buildings. In which, the solution for the velocity, temperature distributions and volumetric airflow, mass- transfer rates were obtained. 
The main objective of this paper is to analytically determine the temperature-, velocity profiles together with volumetric airflow and mass transfer in a rectangular building with multiple upper openings. The effect of indirect flow of air in each of the upper openings were also investigated and the results will be compared with the one in previous intervention given by [2], in order to ascertain the best for optimal ventilation.

\section{BUILDING DESCRIPTION}

The building considered, is un-stratified cross- ventilated rectangular building with multiple upper openings on vertical wall. In which the building has multiple upper vents and one lower opening. Each of the upper opening has an area of $0.7 \mathrm{~m} \times 1.0 \mathrm{~m}$, while the lower opening is $0.7 \mathrm{~m} \times 2.0 \mathrm{~m}$. Dimension of the building is $5.3 m \times 3.6 m \times 2.8 m$ with air as the connecting fluid. The building envelops were separated from one another by a vertical rectangular openings of height $y^{*}$ and width $x_{w}$, which is illustrated in Figure 1 . The density of air in the building is maintained at $\rho_{0}$ with temperature at $\theta$ and pressure $p$.

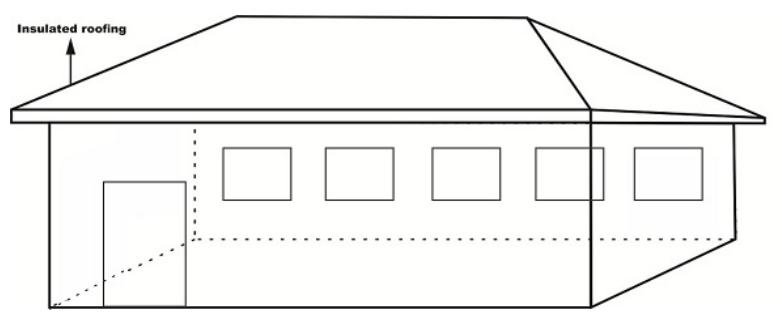

Figure 1: Diagram of un-stratified cross ventilated rectangular building.

\section{MODEL FORMULATION}

Figure 2. shows a schematic diagrams of building, in which the air can infiltrate from outside through the lower opening (doorways) and remove through the upper vents (windows) to the ambient. Figure 3. shows a Schematic diagram of airflow across each of the vertical vents in the presence of indirect flow. From the analysis it has been assumed that the interior temperature in the building is uniform, airflow is at low speed so that it will behave like incompressible fluid (see [8]) and the flow of air is one- dimensional, viscous effect and internal heat source has been neglected $\left(\left(\phi_{v} \ll 1, q \ll 1\right)\right.$.

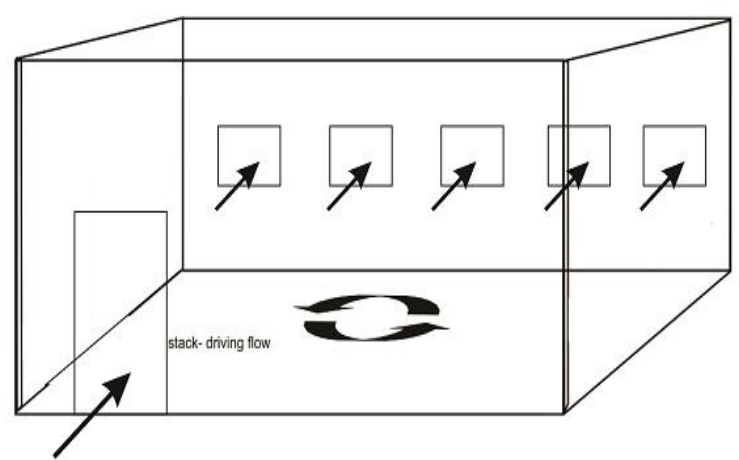

Figure 2: Schematic diagram of airflow in building

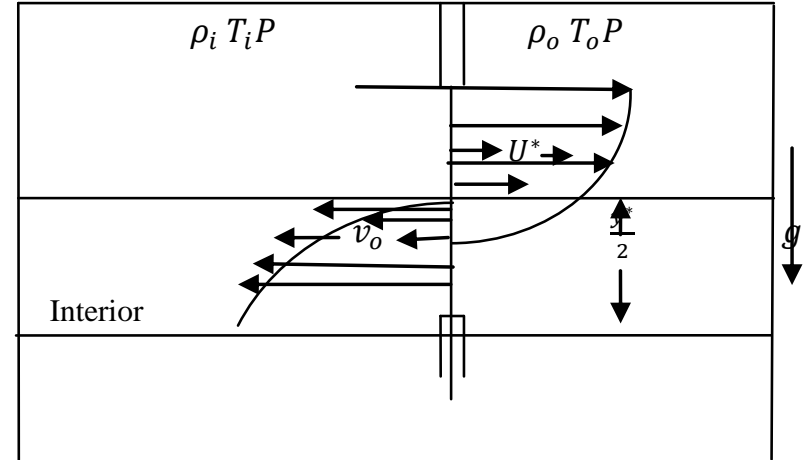

Figure 3: Schematic diagram of airflow across each of the upper vents in the presence of indirect flow

The convective motion induced by stack- driven effect as illustrated in Figure 2 and 3 is described by one dimensional Navier- Stokes Equation with appropriate boundary conditions in which, an approximation of reduced gravity is invoked. The model Equations are written in a dimensionless form and solved analytically by means of separation of variable methods.

$\rho_{0}\left(\frac{d u}{d x_{w}}+\frac{d v_{0}}{d y}\right)=0$

$\rho_{0}\left(u \frac{d u}{d x_{w}}+v_{0} \frac{d u}{d y}\right)=-\frac{d \mathrm{p}}{d x_{w}}+\mu\left(\frac{d^{2} u}{d x_{w}^{2}}+\frac{d^{2} u}{d y^{2}}\right)$

$\rho_{0}\left(u \frac{d \theta}{d x_{w}}+v_{0} \frac{d \theta}{d y}\right)=\frac{k}{c_{p}}\left(\frac{d^{2} \theta}{d x_{w}^{2}}+\frac{d^{2} \theta}{d y^{2}}\right)+\frac{q}{c_{p}} \phi_{v}$

$U=u(y), v_{0}=$ const. $T=\theta(\mathrm{y}), x_{w}=$ const.,$P=$ $p\left(x_{w}\right), \rho_{0}=$ const. $\neq 0$

Equations are (1), (2) and (3) are further simplified by the assumptions, in which mass conservation Equation in (1) is satisfied identically then, Equations (2) and (3) can be reduced to,

$\frac{d U}{d x_{w}}+\frac{d v_{0}}{d y}=0$

$v_{0} \frac{d U}{d y}=g \beta \Delta T+v \frac{d^{2} U}{d y^{2}}$

$v_{0} \frac{d T}{d y}=\alpha \frac{d^{2} T}{d y^{2}}$

With the dimensional boundary conditions as,

$0 \leq y \leq 2, U(y=0)=0, U(y=1)=0, T(y=0)=$ $-\theta_{0}, T(y=1)=1-\theta_{0}$

By scaling $y^{*}$ with $\frac{y}{L}$, velocity, $U^{*}$ with $\frac{U L}{\alpha}, v_{0}{ }^{*}$ with $\frac{v_{0} L}{v}$ and $T^{*}$ with $\frac{T-T_{0}}{\Delta T}$

In dimensionless form the above Equations (1) and (2) may be expressed as,

$\operatorname{Pr} \frac{d^{2} U^{*}}{d y^{* 2}}+C \frac{d U^{*}}{d y^{*}}=-G r T^{*}$ 
$\frac{d^{2} T}{d y^{* 2}}+C \frac{d T^{*}}{d y^{*}}=0$

With the dimensionless boundary conditions as,

$0 \leq y^{*} \leq 1, U^{*}(0)=0, U^{*}(1)=0, T^{*}(0)=-\theta_{0}, T^{*}(1)=$ $1-\theta_{0}$

where, $C=-v_{0}^{*} \operatorname{Pr}, \alpha=\frac{k}{\rho_{0} c_{p}}, v=\frac{\mu}{\rho_{0}}, \operatorname{Pr}=\frac{v}{\alpha}, G r=\frac{L^{3} g \beta T^{*} \Delta T}{v^{2}}$

\section{SOLUTION OF THE}

\section{DIMENSIONLESS MODEL EQUATIONS}

\subsection{Dimensionless temperature profiles}

Equation (10) is homogeneous differential equation (D.E) in which, the D.E and boundary conditions are given by,

$\frac{d^{2} T}{d y^{* 2}}+C \frac{d T^{*}}{d y^{*}}=0$

$T^{*}(0)=-\theta_{0}, T^{*}(1)=1-\theta_{0}$

Equation (10), together with the boundary conditions in (11) yields to,

$$
T^{*}\left(y^{*}\right)=C_{1}+C_{2} e^{-c y^{*}}
$$

The two constant which appear in Equation (12) can be determined by prescribing the boundary condition for the velocity field in Equation (11), thus obtaining,

$C_{1}=\frac{1-\theta_{0}\left(1-e^{-C}\right)}{1-e^{-C}}, C_{2}=-\frac{1}{1-e^{-C}}$,

Inserting equation (13) into (12), yield to the temperature profiles as,

$T^{*}\left(y^{*}\right)=\frac{1-\theta_{0}\left(1-e^{v_{0} P r}\right)-e^{v_{0} P r y^{*}}}{1-e^{v_{0} P r}}$

\subsection{Dimensionless velocity profiles}

Equation (9) is non homogeneous differential equation (D.E) in which, the D.E and boundary conditions are given by,

$\operatorname{Pr} \frac{d^{2} U^{*}}{d y^{* 2}}+C \frac{d U^{*}}{d y^{*}}=-G r T^{*}$

$U^{*}(0)=0, U^{*}(1)=0$

Plugging Equation (14) in Equation (9) yields to,

$\frac{d^{2} U^{*}}{d y^{* 2}}+\frac{C}{P r} \frac{d U^{*}}{d y^{*}}=-\frac{G r}{P r}\left(\frac{1-\theta_{0}\left(1-e^{v_{0} P r}\right)-e^{v_{0} P r y^{*}}}{1-e^{v_{0} P r}}\right)$

Starting with the homogeneous part of Equation (15), one obtained the complementary solution as,

$U_{c}\left(y^{*}\right)=C_{3}+C_{4} e^{-\frac{C}{P r} y^{*}}$,

By employing the variation of parameter methods, one can write the particular solution as,

$U_{p}\left(y^{*}\right)=\frac{G r}{C^{2}\left(1-e^{-C}\right)}\left[\left(\theta_{0}\left(1-e^{-C}\right)-1\right) C y^{*}-e^{-C y^{*}}(1+\right.$
$\left.\left.\frac{P r}{1-P r}\right)+\operatorname{Pr}\left(1-\theta_{0}\left(1-e^{-C}\right)\right)\right]$
The general solution is given by,

$$
\begin{aligned}
& U^{*}\left(y^{*}\right)=C_{3}+C_{4} e^{-\frac{C}{P r} y^{*}}+\frac{G r}{C^{2}\left(1-e^{-C}\right)}\left[\left(\theta_{0}\left(1-e^{-C}\right)-\right.\right. \\
& \text { 1) } \left.C y^{*}-e^{-C y^{*}}\left(1+\frac{P r}{1-P r}\right)+\operatorname{Pr}\left(1-\theta_{0}\left(1-e^{-C}\right)\right)\right]
\end{aligned}
$$

The two constant which appear in Equation (18) can be determined by prescribing the boundary condition for the velocity field in Equation (11), thus obtaining,

$$
\begin{aligned}
& C_{3}=\frac{\left(1+\frac{P r}{1-P r}\right)\left(e^{-C}-e^{-\frac{C}{P r}}\right)+\left(1-\theta_{0}\left(1-e^{-C}\right)\right)\left(C-P r\left(1-e^{-\frac{C}{P r}}\right)\right)}{C^{2}\left(1-e^{-C}\right)\left(1-e^{-\frac{C}{P r}}\right)}, C_{4}= \\
& -\frac{1}{C^{2}\left(1-e^{-C}\right)\left(1-e^{-\frac{C}{P r}}\right)}\left[\left(1+\frac{P r}{1-P r}\right)\left(e^{-C}-1\right)+C(1-\right. \\
& \theta 01-e-C
\end{aligned}
$$

$$
\begin{aligned}
& U^{*}\left(y^{*}\right)=\frac{G r}{C^{2}\left(1-e^{-C}\right)\left(1-e^{-\frac{C}{P r}}\right)}\left[( 1 + \frac { P r } { 1 - P r } ) \left(e^{-C}-e^{-\frac{C}{P r}}-\right.\right. \\
& e-C P r y * e-C-1-e-C y * 1-e-C P r+1-\theta 01-e-C C-\operatorname{Pr} 1- \\
& e-C P r-C e-C P r y *+1-e-C \operatorname{Pr} P r-C y^{*} \\
& 20
\end{aligned}
$$

\subsection{Dimensionless volumetric airflow}

The volumetric airflow is defined in Equation (21) below,

$Q^{*}\left(y^{*}\right)=A^{*} c_{d} \int_{s=0}^{s=\frac{y^{*}}{2}} U^{*}(s) d s$

Where, $s$ is a dummy variable.

The results for Equation (21) yields to volumetric airflow as,

$$
\begin{aligned}
& Q^{*}\left(y^{*}\right)=\frac{A^{*} G_{r} c_{d}}{C^{2}\left(1-e^{-C}\right)\left(1-e^{-\frac{C}{P r}}\right)}\left[( 1 + \frac { P r } { 1 - P r } ) \left[\left(e^{-C}-e^{-\frac{C}{P r}}\right) \frac{y^{*}}{2}+\right.\right. \\
& \text { Pre }-C-1 e-C 2 \text { Pry } * C+1-e-C \text { Pre }-C y * 2 C-\text { Pre }-C-1 C-1-e \operatorname{PrC} \\
& +1-\theta 01-e-C-P r-C P r+1-e-C P r y * 2+P r e-C 2 P r y *+1-e-C P \\
& r \operatorname{Pry} * 2-C y * 28-P r \\
& 22
\end{aligned}
$$

\subsection{Mass Transfer Dimensionless mass transfer}

The mass transfer is defined in Equation (23) below as,

$m^{*}\left(y^{*}\right)=\rho_{0} Q^{*}\left(y^{*}\right)$

By plugging Equation (22) in (23), one obtains the mass transfer as,

$$
\begin{aligned}
& m^{*}\left(y^{*}\right)=\frac{\rho_{0} A^{*} G_{r} C_{d}}{C^{2}\left(1-e^{-C}\right)\left(1-e^{-\frac{C}{P r}}\right)}\left[( 1 + \frac { P r } { 1 - P r } ) \left[\left(e^{-C}-e^{-\frac{C}{P r}}\right) \frac{y^{*}}{2}+\right.\right. \\
& \left.\operatorname{Pr}\left(e^{-C}-1\right) \frac{e^{-\frac{C}{2 P r} y^{*}}}{C}+\left(1-e^{-\frac{C}{P r}}\right) \frac{e^{-C \frac{y^{*}}{2}}}{C}-\operatorname{Pr} \frac{\left(e^{-C}-1\right)}{C}-\frac{\left(1-e^{P r}\right)}{C}\right]+
\end{aligned}
$$




$$
\begin{aligned}
& \left(1-\theta_{0}\left(1-e^{-C}\right)\right)\left[-\operatorname{Pr}\left(-\frac{C}{P r}+\left(1-e^{-\frac{C}{P r}}\right)\right) \frac{y^{*}}{2}+\operatorname{Pr} e^{-\frac{C}{2 P r} y^{*}}+\right. \\
& \left.\left.\left(1-e^{-\frac{C}{P r}}\right)\left(\operatorname{Pr} \frac{y^{*}}{2}-C \frac{y^{* 2}}{8}\right)-\operatorname{Pr}\right]\right]
\end{aligned}
$$

\section{ASYMPTOTIC BEHAVIOR, COMPARISON WITH THE PREVIOUS RESULTS AND DISCUSSION OF THE RESULTS}

In this section the main features of the solutions found in the previous section (4.0) and comparison with the previous results will be discussed. This is done in order to see the effect of changes of effective thermal coefficient $\theta_{0}$, Prandtl number $\mathrm{Pr}$, and Grashof number $\mathrm{Gr}$ to the overall distributions, while keeping other operating conditions and parameters fixed, and ascertain the best one for optimal natural ventilation.

A Physical interpretation of dimensionless temperature profiles for three incremental values of $\theta_{0}, P r$ are presented in Figure 4 and 5 . In which Figure 4 depicts the effect of effective thermal coefficient $\theta_{0}$ on temperature profiles $T^{*}$. It is observed that, as effective thermal coefficient $\theta_{0}$ increases the corresponding temperature profiles $T^{*}$ across the opening decreases. Due to the opposing flow in each of the upper openings in the domain, the effect of buoyancy forces is found to be strong. Figure 5 depicts the effect of $\operatorname{Pr}$ on temperature profiles $T^{*}$. It is observed that, as $P r$ increases the corresponding temperature profiles $T^{*}$ increases. The obvious features to be observed is that, the temperature distributions are within comfortable condition and all the lines of flow for temperature profiles are linearly and uniformly distributed. The greater vertical distance between the openings, and the greater temperature difference between the interior and exterior of the domain, the stronger is the effect of the buoyancy forces. Therefore, it is found that the best value of $T^{*}$ for optimal natural ventilation is when $\theta_{0}=0.01$.

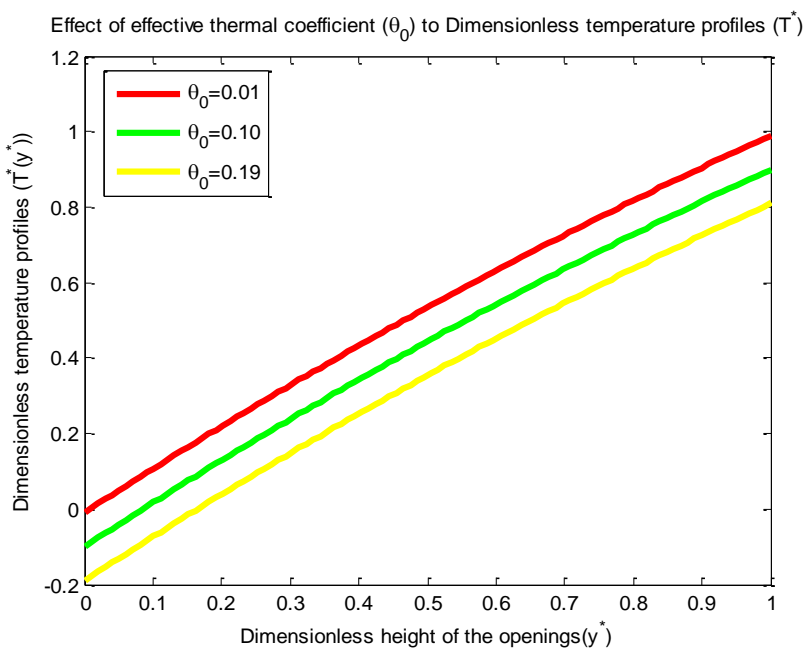

Figure 4: Dimensionless temperature profiles $T^{*}$ versus $\boldsymbol{y}^{*}$ at different values of $\boldsymbol{\theta}_{0}=0.01,0.03,0.05$.

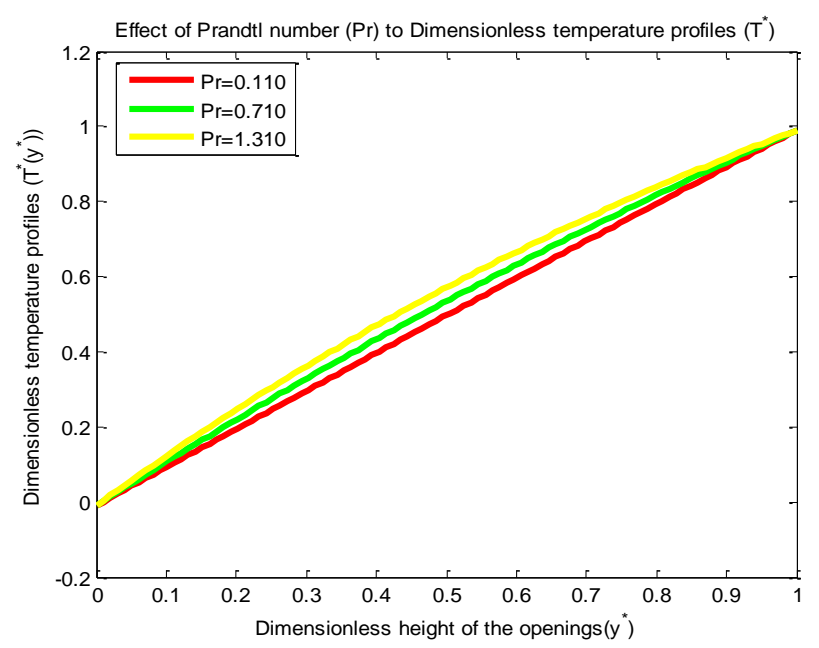

Figure 5: Dimensionless temperature profiles $\boldsymbol{T}^{*}$ versus $\boldsymbol{y}^{*}$ at different values of $\mathrm{Pr}=0.110,0.710,1.310$.

A Physical interpretation of dimensionless velocity profiles for three incremental values of $\theta_{0}, P r, G r$ are presented in Figure 6,7 and 8 . Figure 6 depicts the effect of effective thermal coefficient $\theta_{0}$ on velocity profiles $U^{*}$. It is observed that, as effective thermal coefficient $\theta_{0}$ increases the corresponding $U^{*}$ decreases. Figure 7 depicts the effect of $\mathrm{Pr}$ on velocity profiles $U^{*}$. It is observed that, as $P r$ increases the corresponding $U^{*}$ decreases. Figure 8 depicts the effect of $\mathrm{Gr}$ on velocity profiles $U^{*}$. It is observed that, as $G r$ increases the corresponding $U^{*}$ increases. Therefore, the main feature to be observed is that, as the temperature changes increases the corresponding airflow is also increases this leads to the increase in velocity profiles. Therefore, it is found that the best value of $U^{*}$ for optimal natural ventilation is when

$\theta_{0}=0.01$

Effect of effective thermal coefficient $\left(\theta_{0}\right)$ to Dimensionless velocity profiles $\left(U^{\star}\right)$

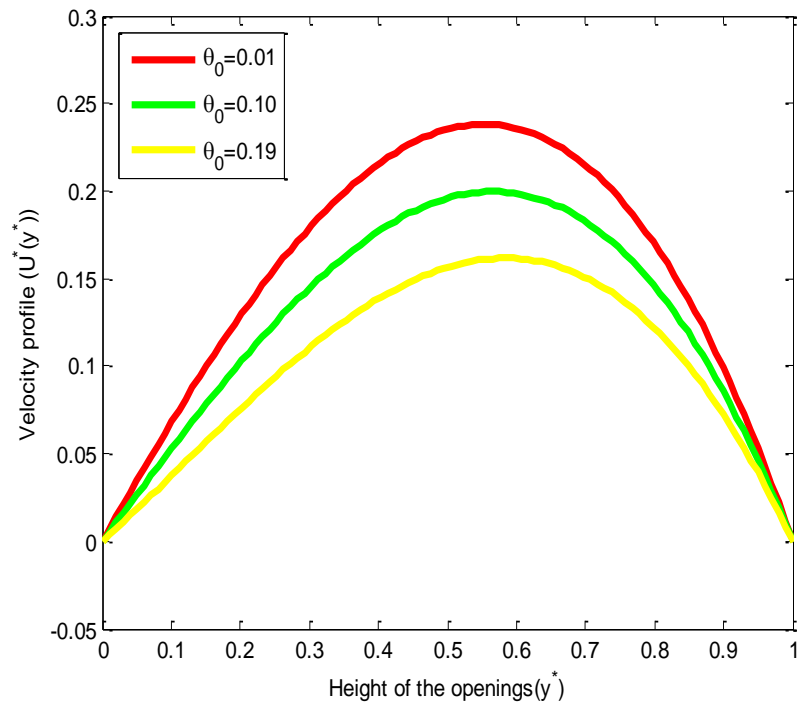


Figure 6: Dimensionless velocity profiles $U^{*}$ versus $y^{*}$ at different values of $\theta_{0}=0.01,0.03,0.05$.

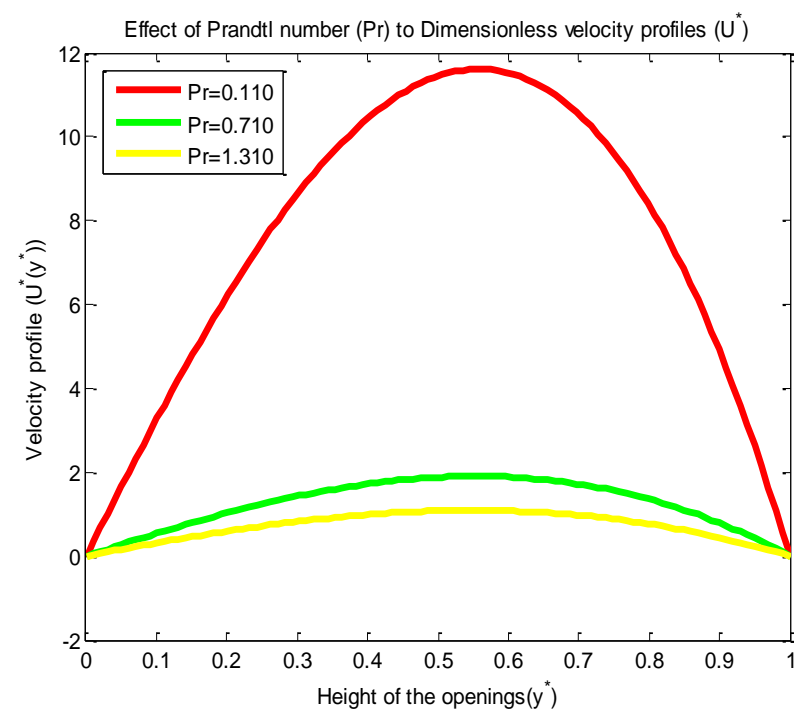

Figure 7: Dimensionless velocity profiles $U^{*}$ versus $y^{*}$ at different values of $\operatorname{Pr}=0.110,0.710,1.310$.

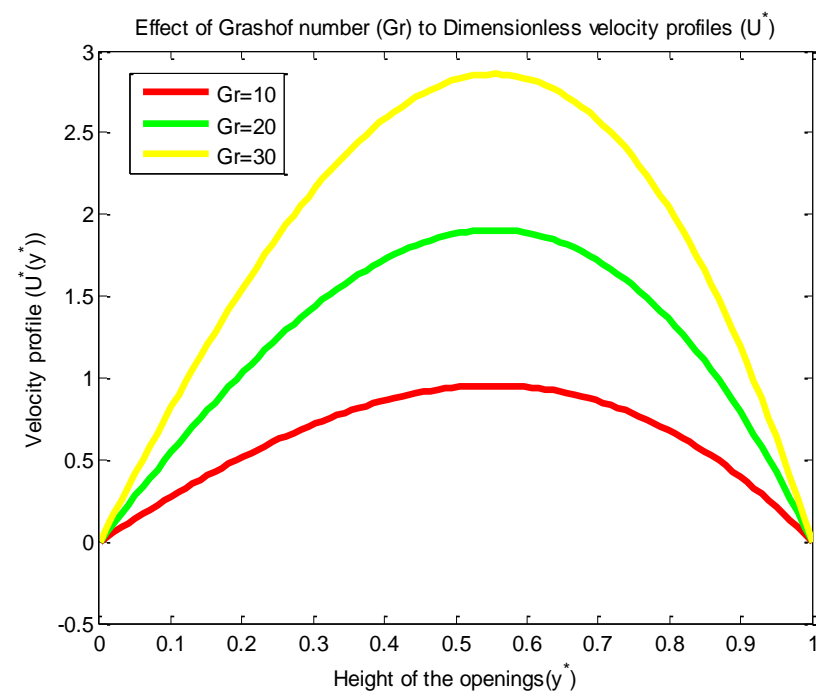

Figure 8: Dimensionless velocity profiles $U^{*}$ versus $y^{*}$ at different values of $G r=10,20,30$.

A Physical interpretation of dimensionless volumetric airflow for three incremental values of $\theta_{0}, P r, G r$ are presented in Figure 9, 10, and 11. In which Figure 9 depicts the effect of effective thermal coefficient $\theta_{0}$ on volumetric airflow $Q^{*}$. It is observed that, as effective thermal coefficient $\theta_{0}$ increases the corresponding $Q^{*}$ decreases. Figure 10 depicts the effect of $\mathrm{Pr}$ on volumetric airflow $Q$. It is observed that, as $\operatorname{Pr}$ increases the corresponding $Q$ decreases. Figure 11 depicts the effect of $G r$ on volumetric airflow $Q^{*}$. It is observed that, as $G r$ increases the corresponding $Q^{*}$ increases. The main feature to be observed is that, as the velocity of the airflow increases the corresponding the volumetric airflow is decreases. Therefore, it is found that the best value of $Q^{*}$ for optimal natural ventilation is when $\theta_{0}=0.01$.

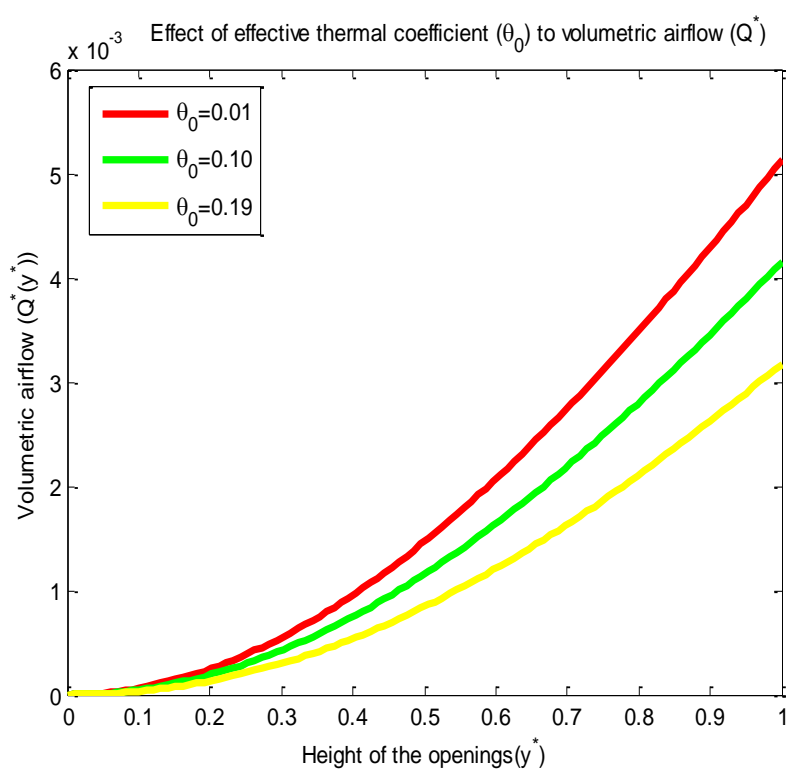

Figure 9: Dimensionless volumetric airflow $Q^{*}$ versus $y^{*}$ at different values of $\theta_{0}=0.01,0.03,0.05$.

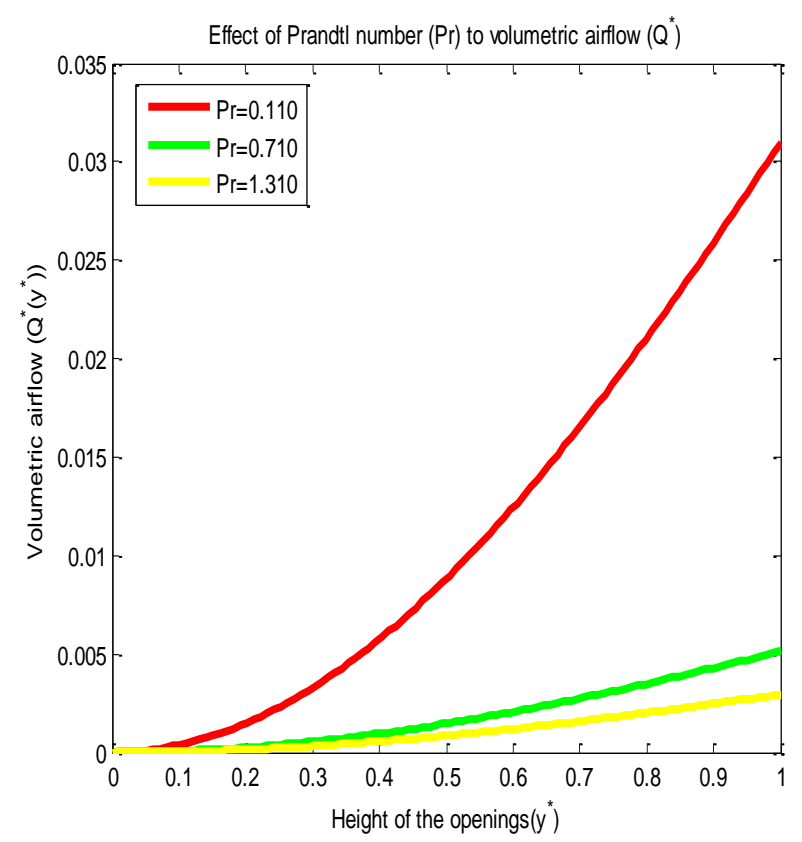

Figure 10: Dimensionless volumetric airflow $Q^{*}$ versus $y^{*}$ at different values of $P r=0.110,0.710,1.310$. 


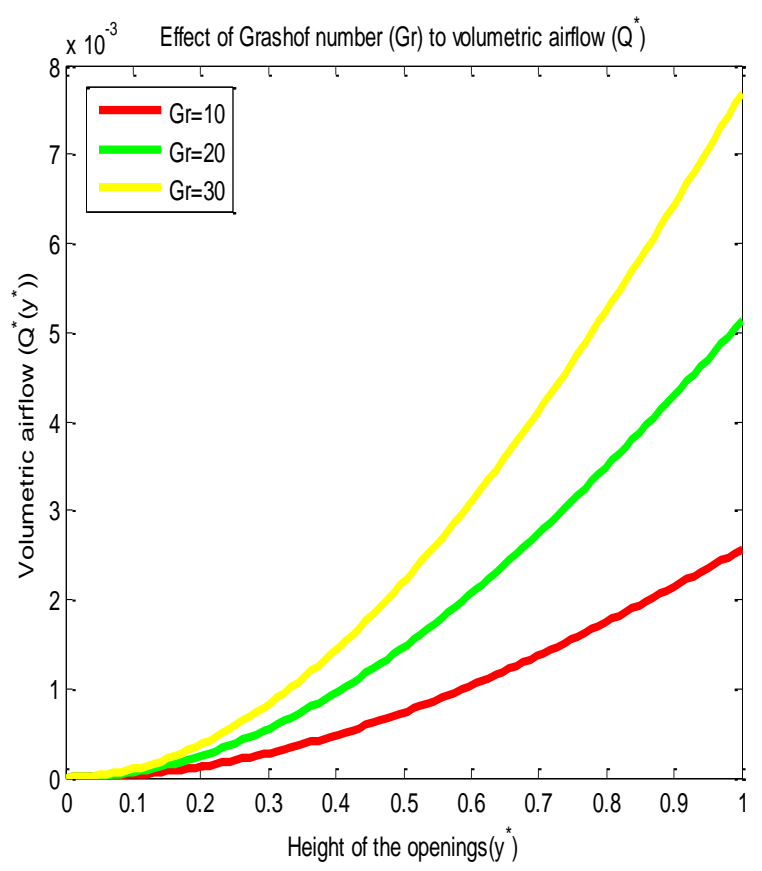

Figure 11: Dimensionless volumetric airflow $Q^{*}$ versus $\boldsymbol{y}^{*}$ at different values of $G r=10,20,30$.

A Physical interpretation of dimensionless mass transfer for three incremental values of $\theta_{0}, \mathrm{Pr}, \mathrm{Gr}$ are presented in Figure 12,13 , and 14. In which Figure 12 depicts the effect of effective thermal coefficient $\theta_{0}$ on mass transfer $m^{*}$. It is observed that, as effective thermal coefficient $\theta_{0}$ increases the corresponding $m^{*}$ decreases. Figure 13 depicts the effect of $\mathrm{Pr}$ on mass transfer $m^{*}$. It is observed that, as $\mathrm{Pr}$ increases the corresponding $m^{*}$ decreases. Figure 14 depicts the effect of $G r$ on mass transfer $m^{*}$. It is observed that, as $G r$ increases the corresponding $m$ increases. The main feature to be observed as the velocity of airflow increases the corresponding the volumetric airflow is also decreases this leads to the increase in mass transfer. Therefore, it is found that the best value of $m^{*}$ for optimal natural ventilation is when $\theta_{0}=0.01$.

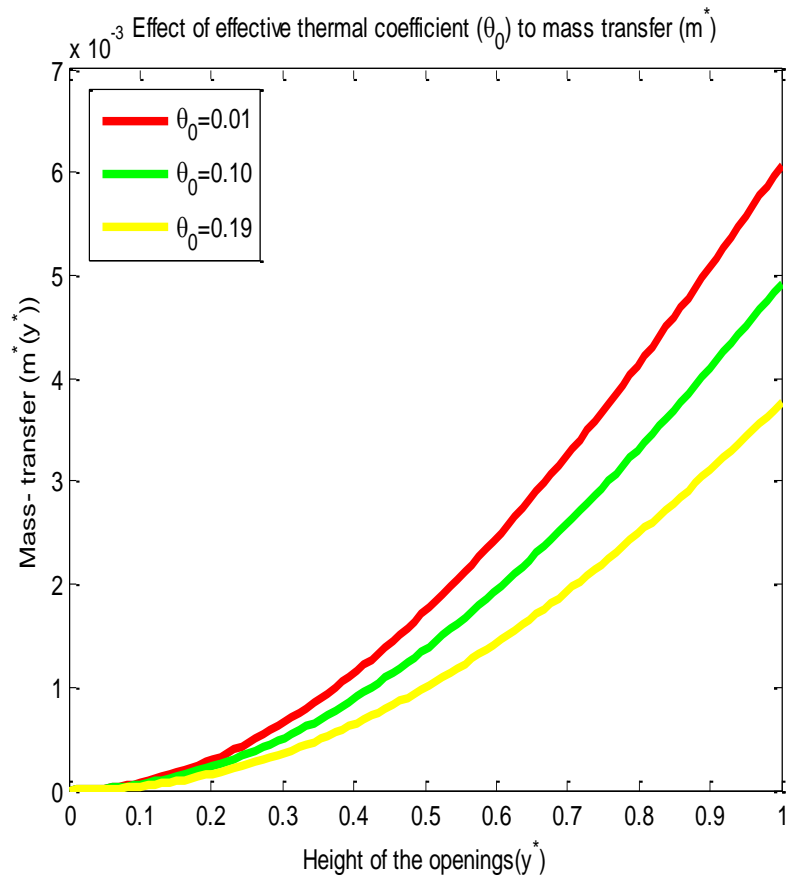

Figure 12: Dimensionless mass transfer $m^{*}$ versus $y^{*}$ at different values of $\theta_{0}=0.01,0.03,0.05$.

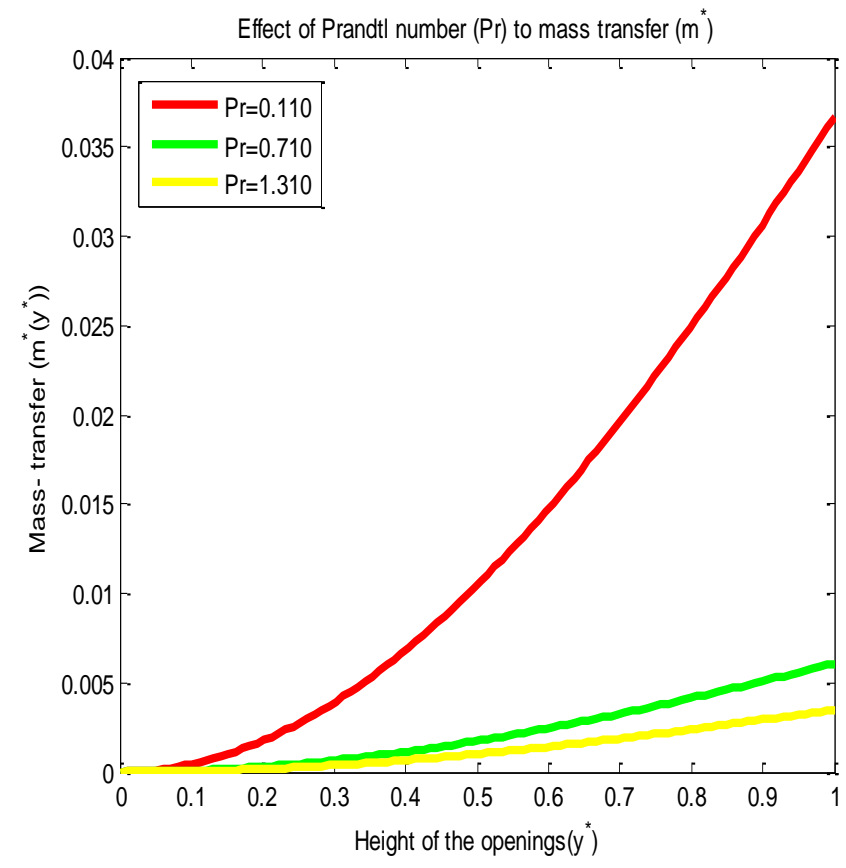

Figure 13: Dimensionless mass transfer $\boldsymbol{m}^{*}$ versus $y^{*}$ at different values of $P r=0.110,0.710,1.310$. 


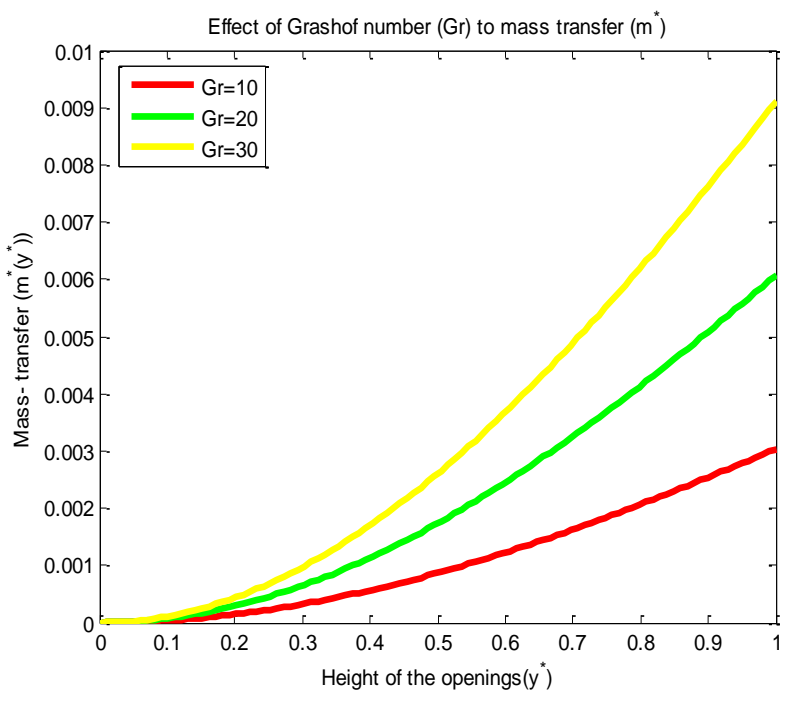

Figure 14: Dimensionless mass transfer $m^{*}$ versus $y^{*}$ at different values of $G r=10,20,30$.

The comparison between developed study and the one studied by [2] is done in order to see the main contributions from the Developed study. A Physical interpretation of dimensionless velocity profiles is presented in Figure 15. In which Figure 15 depicts the comparison between $U^{*}$ and $U^{*} 1$. It is observed that, the effect of parameters in the $U^{*}$ is more effective than the one in the $U^{*} 1$, in which, the airflow moving at $U^{*}$ is higher than the one in $U^{*} 1$. Therefore, it is found that the best value of velocity profiles for optimal natural ventilation is found to be in developed study $\left(U^{*}\right)$.

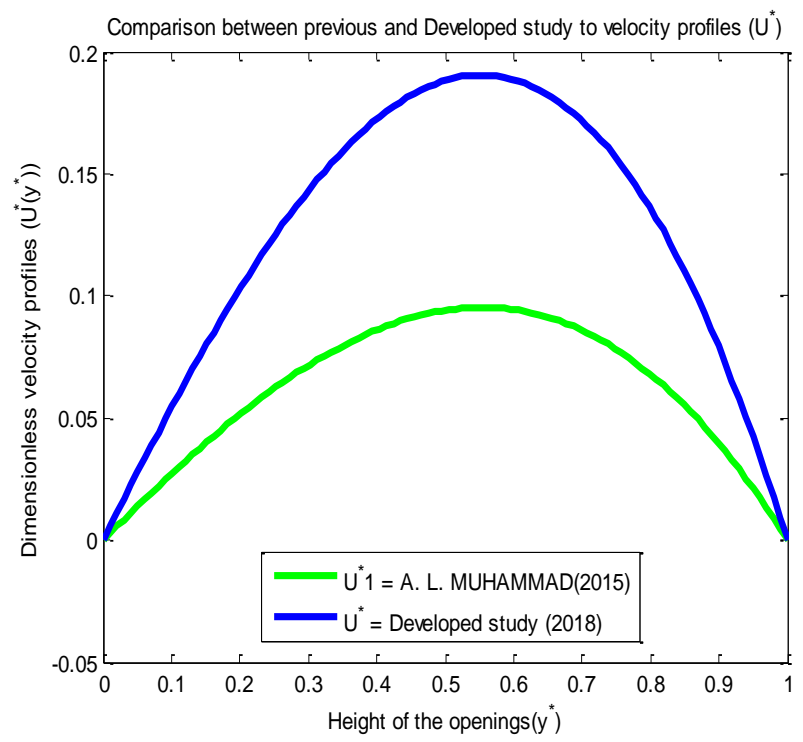

Figure 15: Comparison between velocity profiles $U^{*}$ and $U^{*} 1$.

A Physical interpretation of dimensionless volumetric airflow is presented in Figure 16. In which Figure 16 depicts the comparison between $Q^{*}$ and $Q^{*} 1$. It is observed that, the effect of parameters in the $Q^{*}$ is more effective than the one in the $Q^{*} 1$, in which, due to the strong effect of buoyancy forces effect the volumetric airflow $Q^{*}$ in the building envelope is much more higher than the one in $Q^{*} 1$. Therefore, it is found that the best value of volumetric airflow for optimal natural ventilation is found to be in developed study $\left(Q^{*}\right)$.

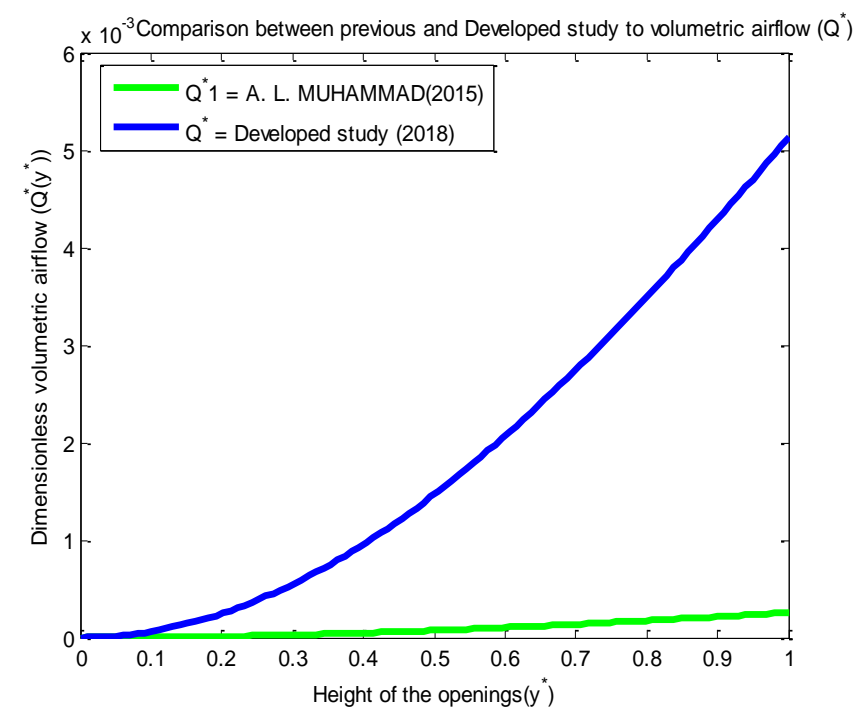

Figure 16: Comparison between volumetric airflow $Q^{*}$ and $Q^{*} 1$.

A Physical interpretation of dimensionless mass transfer is presented in Figure 17. In which Figure 17 depicts the comparison between $m^{*}$ and $m^{*} 1$. It is observed that, the effect of parameters in the $m^{*}$ is more effective than the one in the $m^{*} 1$, in which, the mass transfer $m^{*}$ is much more higher than the one in $m^{*} 1$. Therefore, it is found that the best value of volumetric airflow for optimal natural ventilation is found to be in developed study $\left(m^{*}\right)$.

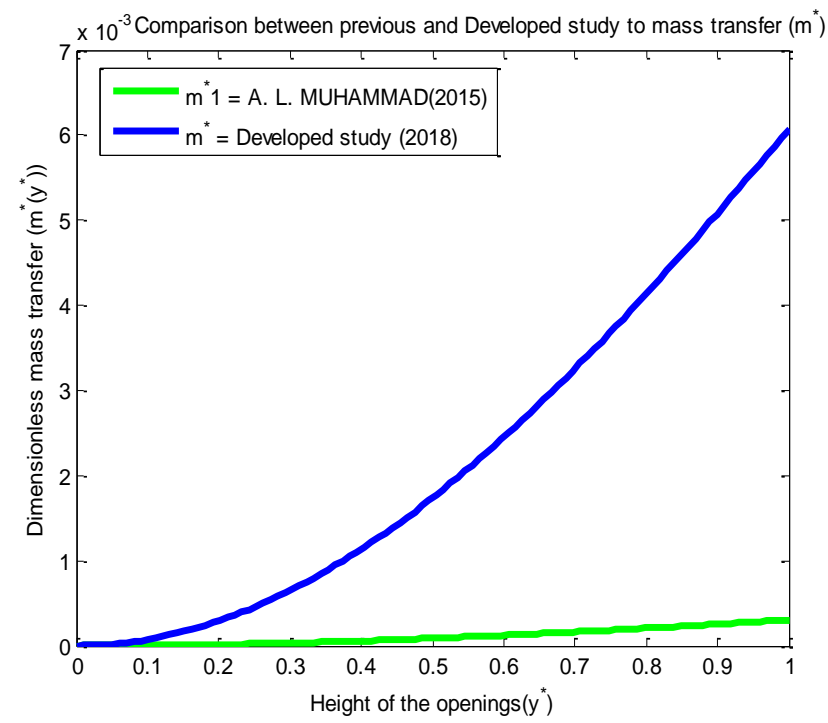

Figure 17: Comparison between mass transfer $m^{*}$ and $m^{*} 1$.

\section{CONCLUSION}

Considerable research efforts have been made in the developed study on understanding the airflow process through openings on vertical wall. In this paper, we studied airflow process through multiple upper vents in un-stratified 
rectangular building in the presence of indirect flow and developed the explicit expressions for velocity and temperature profiles together with volumetric airflow and mass transfer. We performed comparison based on assume numerical values and parameter values of [2]. From the simulations in Figures 15-17, our Developed study is better and more efficient for ventilation. In which, the greater number of vertical vents and the greater temperature difference between the interior and exterior of the building, the stronger is the effect of the buoyancy forces. Therefore, the expected aim and the set of objectives for the study were achieved.

The paper leads to the following conclusions;

$>$ A decrease in effective thermal coefficient $\theta_{0}$ results in an increase in temperature profiles $T^{*}$ across the openings. The temperatures profiles $T^{*}$ is more sensitive at lower values of effective thermal coefficient $\theta_{0}$. Therefore, the main features to be observed is that the temperature profiles $T^{*}$ was within comfortable conditions.

$>$ A decrease in effective thermal coefficient $\theta_{0}$ results in an increase in velocity profiles $U^{*}$ across the openings. The velocity profiles $U^{*}$ is more sensitive at lower values of effective thermal coefficient $\theta_{0}$. Therefore, the main feature to be observed as the temperature changes increases the corresponding the airflow is also increases this leads to the increase in velocity profiles.

$>$ An increase in effective thermal coefficient $\theta_{0}$ results in an decrease in volumetric airflow $Q^{*}$. The volumetric airflow $Q^{*}$ is more sensitive at lower values of effective thermal coefficient $\theta_{0}$. Therefore, the main feature to be observed as the velocity of the airflow increases the corresponding the volumetric airflow is decreases.

$>$ A decrease in effective thermal coefficient $\theta_{0}$ results in an increase in mass transfer $m^{*}$. The mass transfer $m^{*}$ is more sensitive at lower values of effective thermal coefficient $\theta_{0}$. Therefore, the main feature to be observed as the velocity of airflow increases the corresponding the volumetric airflow is also decreases this leads to the increase in mass tranfer.

$>$ The greater number of vertical vents and the greater temperature difference between the interior and exterior of the building, the stronger is the effect of the buoyancy forces.

The model is only valid for un-stratified rectangular ventilated building with multiple upper vents at the same height.

\section{ACKNOWLEDGMENTS}

This study is for Undergraduate Research Experience at Kano University of Science and Technology, Wudil. One of the author's named D. A. Gano is an honors degree student from Mathematics Department, KUST- Wudil and is grateful, to authorities of KUST- Wudil for granting him leave to conduct the research.

\section{BIBLIOGRAPHY}

8.1 Nomenclature

$C_{1}, C_{2}, C_{3}, C_{4}$ Coefficients;

$A^{*} \quad$ Total area of the openings;

$x_{w} \quad$ Constant width of the openings along $x$-direction ;

$y \quad$ Dimensional height of the openings along $y$-direction

$y^{*} \quad$ Dimensionless height of the openings;

$v_{0}$ Constant indirect velocity along width of the upper vents;

$c_{d} \quad$ Discharge coefficient;

$c_{p} \quad$ Specific heat capacity of air;

$q \quad$ Internal heat source;

$g \quad$ Acceleration due to gravity;

$P \quad$ Air pressure;

U Dimensional velocity profile;

$U^{*} \quad$ Dimensionless velocity profiles;

$m^{*} \quad$ Dimensionless mass - transfer;

$m^{*} \quad$ Dimensionless volumetric airflow;

$U_{C} \quad$ Complimentary solutions;

$U_{p} \quad$ Particular solutions;

$\frac{y^{*}}{2} \quad$ Neutral height;

$s \quad$ Dummy variable;

$L \quad$ Length scale of the height of the opening;

\subsubsection{Greek Symbols}

$\alpha$

Thermal diffusivity;

$\phi_{v} \quad$ Viscous dissipation;

$v \quad$ Kinematic viscosity;

$k$

Thermal conductivity;

$\beta$

Thermal expansion coefficient;

$\theta_{0} \quad$ Effective thermal coefficient;

$\Delta \theta \quad$ Dimensional change of air temperature;

$\theta \quad$ Dimensional temperature of air;

$T^{*} \quad$ Dimensionless temperature profiles;

$\rho_{0} \quad$ Constant density of the air; 


\subsubsection{Dimensionless parameter}

$\mathrm{Pr}$ Prandtl number;

\subsubsection{Subscripts}

w width;

\section{REFERENCES}

[1] Allocca, C., Chen, Q., and Glicksman, L.R. (2003). Design analysis of single-sided natural ventilation Energy and Buildings. 35(8), 785- 795.

[2] A. L. Muhammad and A. B. Baffa 2015. Airflow process across vertical vents induced by stack- driven effect with an opposing flow in one of the upper openings. International Journal of Computer Application (IJCA). Volume 123(1). 1- 8.

[3] A. L. Muhammad and A. B. Baffa and M. Z. Ringim 2016. Investigation of stack- driven airflow through rectangular cross- ventilated building with two openings using analytic technique. International Journal of Computer Application (IJCA). Volume 141(6). 5- 11.

[4] Andrew Acred, Gary R. Hunt 2014. A simplified mathematical approach for modelling stack ventilation in multi-compartment buildings. Builing and Environment $71,121-130$.

[5] Barakat, S.A., (1987) . Inter- zone convection heat transfer in building: a review. J. Solar Energy, 109, 7178.
[6] Brown, W.G., and Salvason, K.R., (1962). Natural convection through rectangular openings in partitionspart I: vertical partitions. Int. J. Heat and mass transfer , 5, 859- 868 .

[7] C.L. Chow 2010. Air flow rate across vertical opening induced by room heat sources. International Journal on Architectural Science Volume 8, Number 1.11- 16.

[8] Daniel, N. R. (2005). Mathematical modeling of wind forces. Department of theoretical and applied mechanics, University of Illinois at Urbana- Champaign. USA. 1 14.

[9] Liang Chung James Lo, 2012. Predicting wind driven cross ventilation in buildings with small openings. Doctoral thesis. University of Texas U. S. A.

[10] M.Santamouris, A. Argiriou, D. Asimakopoulos, N. Klitsikas, A. Dounis 1995. Heat and Mass- Transfer through large openings by natural convection. Energy and Buildings 23.

[11] Roberto Fuliotto et al. (2010)," Experimental and Numerical analysis of heat transfer and airflow on an interactive building façade". Energy and Buildings. 42(1), 23- 28.

[12] Yuguo Li, Angelo Delsante, Je Symons 2000. Prediction of natural ventilation in buildings with large openings. Built. and Environment 35, 191- 206. 